\title{
Linear-Assisted DC/DC Converters with Modified Current-Mode Control Applied to Photovoltaic Solar Systems
}

\author{
Herminio Martínez-García \\ Barcelona College of Industrial Engineering (EUETIB) \\ Department of Electronics Engineering \\ Technical University of Catalonia (UPC). BarcelonaTech \\ C/ Comte d'Urgell, $\mathrm{n}^{\circ} 187$ \\ 08036 - Barcelona. SPAIN \\ Phone Number: +34.93.413.72.90; Fax Number: +34.93.413.74.01; E-mail: herminio.martinez@upc.edu
}

\begin{abstract}
This article shows the proposal of a current-mode one-cycle control for linear-assisted DC/DC converters. Linearassisted $\mathrm{DC} / \mathrm{DC}$ converters are structures that allow to take advantages of the two classic alternatives in the design of power supply systems: voltage linear regulators (classic NPN topology or LDO -low dropout-) and switching DC/DC converters. The current-mode one-cycle control technique is proposed in order to obtain the duty cycle of the linear-assisted converter switch. The proposed structure can provide an output with suitable load and line regulations. Thus, the paper shows the design and simulation results of the proposed current-mode one-cycle linear-assisted converter.
\end{abstract}

\section{Key words}

Power Electronics; DC-DC switching power converters, linear-assisted DC-DC converters.

\section{Introduction}

Linear-assisted DC/DC converters (also known as linearswitching hybrid converters) are circuital structures that present an increasing interest for the implementation of power supply systems that require two demanding design specifications: (1) high slew-rate of the output current and (2) high current consumption by the output load. This it is the case of the systems based on the modern microprocessors and DSPs, where both requirements converge [1], [2].

These linear-switching hybrid converters are able to combine the well-known advantages of the two existing typical alternatives for the implementation of DC/DC voltage regulators or converters, diminishing as well their disadvantages. These two alternatives are known largely: (1) the use of voltage series linear regulators (classic standard NPN - or nMOS- topologies and LDO) have been widely used for some decades [3]-[5], and (2) the DC/DC switching converters, thanks to which high current power supply systems can be obtained [6]-[8]. Linear-assisted DC/DC converters can be implemented on printed circuits using discrete components. Nevertheless, they are also an attractive alternative susceptible to be integrated in onchip power supply systems as a part of power management systems.

An important part of these converters is their controller. Some alternatives are present [9]-[12]. However, the nonlinear control technique known as one-cycle control ([13], [14]) is proposed in current article. One-cycle control takes advantage of the pulsed and nonlinear nature of switching converters and achieves instantaneous dynamic control of the average value of a switched variable; more specifically, it takes only one switching cycle for the average value of the switched variable to reach a new steady state after a transient. There is no steady-state error or dynamic error between the control reference and the average value of the switched variable. This technique provides fast dynamic response, excellent power source disturbance rejection, robust performance, and automatic switching error correction.

Though one-cycle control has so many advantages, it is infirmness for load disturbance. However, the inclusion in the linear-assisted converter of a voltage linear regulator provides the suitable load regulation thank to a second loop included in the linear regulator block.

\section{Basic Topology of a Linear-Assisted DC/DC Converter}

The basic scheme of a single output linear-assisted converter is shown in Figure 1 [11], [12]. This structure consists, mainly, of a voltage linear regulator in parallel with a step-down switching DC/DC converter. In this type of converters, the value of the output voltage, supposed constant, is fixed with good precision by the voltage linear regulator. The current flowing through this linear regulator is constantly sensed by the current sense element $R_{m}$. Based on its value, the controller activates or 
not the output of comparator $C M P_{1}$ that, as well, leads to the switch element of the DC/DC switching converter. Therefore, notice that the current through the linear regulator constitutes a measurement of the error of the power supply system.

The power stage (that is, the switching converter) injects in the output the necessary current to force to a minimum value (not necessarily zero) the current flowing through the linear regulator. As a consequence, it is obtained, altogether, a power supply system where the switching frequency comes fixed, among other parameters (such as the possible hysteresis of the analog comparator), by the value of the current through the linear regulator. On the other hand, the output voltage value is fixed by the voltage linear regulator.

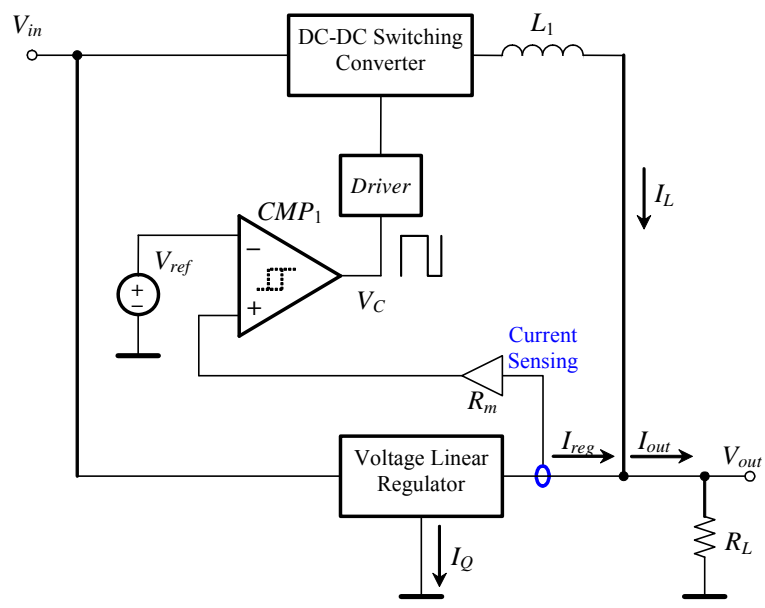

Fig. 1. Block diagram of the proposed linear-assisted converter.

In the linear-assisted converter in Figure 2, in which the switching converter is a step-down type [11], [12], the linear regulator consists of a push-pull output stage (transistors $Q_{2 a}$ and $Q_{2 b}$ ). In this strategy, the main objective of the DC/DC switching converter is to provide almost all the load current in steady-state conditions (to obtain a good efficiency of the whole system). Thus, in steady state, the linear regulator provides a little part of the load current, maintaining the output voltage to an acceptable constant value.

As a matter of fact, if the current demanded by the load $I_{\text {out }}$ is inferior to a maximum value of current, which we will denominate switching threshold current, $I_{\gamma}$, the output of comparator $C M P_{1}$ will be at low level, disabling the DC/DC switching converter and, thus, the current flowing through inductor $L_{1}$ will be zero (Figure 3 ). Therefore, the voltage linear regulator supplies the load $R_{L}$, providing all the output current $\left(I_{\text {reg }}=I_{\text {out }}\right)$. However, when the current demanded by the load overpasses this current limit $I_{\gamma}$, automatically the output of the comparator will pass to high level, causing that the current through the inductance $L_{1}$ supplies almost the total load output current.

\section{One-Cycle Control Concept}

One cycle control was proposed by Keyue M. Smedley in 1991 and realized initially in buck PWM converter [13]-
[15]. DC/DC switching converters with one-cycle control reject input perturbations in only one switching cycle and follow the control reference instantly. It is said that onecycle control is universal and can be applied directly to switching converters in either PWM or quasi resonant modes [15], [16]. From then on, with one-cycle control, boost converter, Cûk converter, three-phase PFC converter and three-phase boost rectifier have been presented. During this period, a general-purpose feedfodward one cycle controller was also advanced.

One-cycle control theory is shown in figure 4, and its operating waveforms are shown in figure 5.

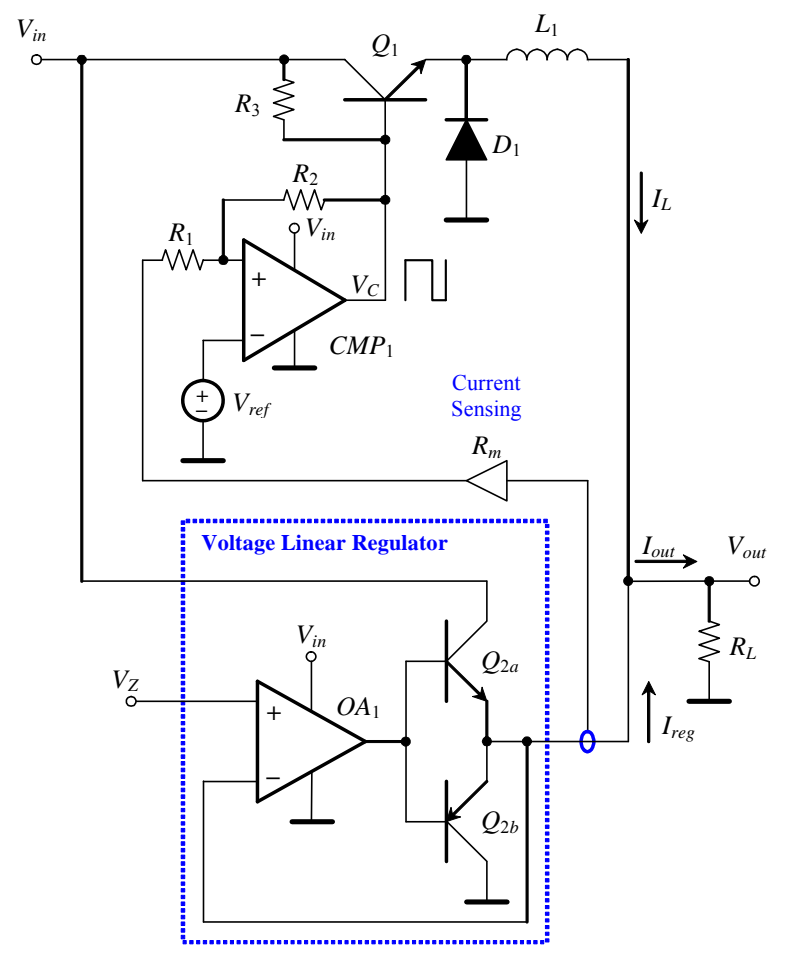

Fig. 2. Basic structure of the proposed linear-assisted DC/DC converter.

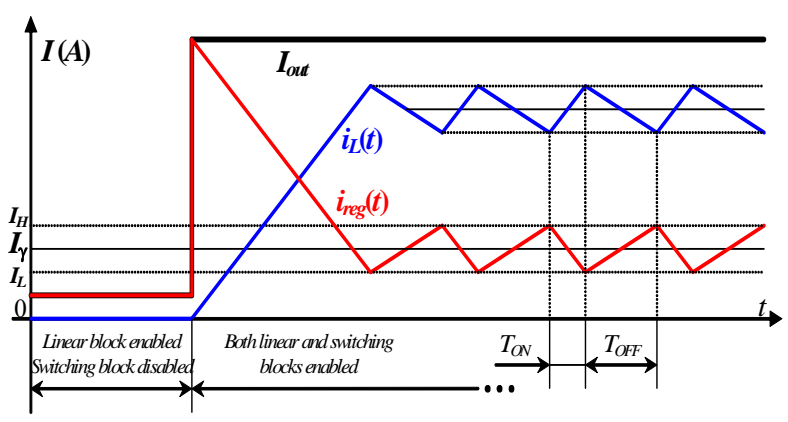

Fig. 3. Principle of operation of the proposed linear-assisted DC/DC converter.

\section{Topology of the Current-Mode One- Cycle Linear-Assisted DC/DC Converter}

Based on the linear-assisted DC/DC converter, the structure of the proposed linear-assisted DC/DC converter with current-mode one-cycle control strategy is 
shown in Figure 6. In this figure we can observe the linear regulator, the switching $\mathrm{DC} / \mathrm{DC}$ converter and the control loop that fixes the duty cycle of the switch element $Q_{1}$.

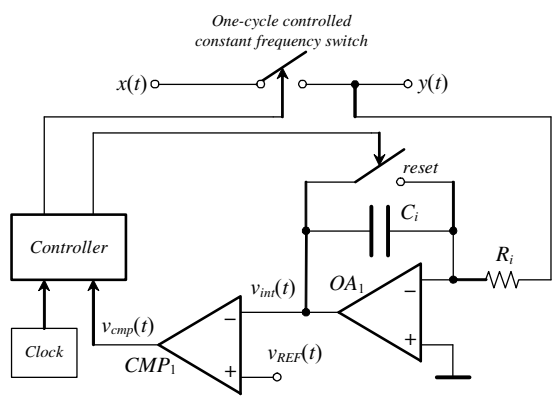

Fig. 4. Basic scheme of one-cycle control.

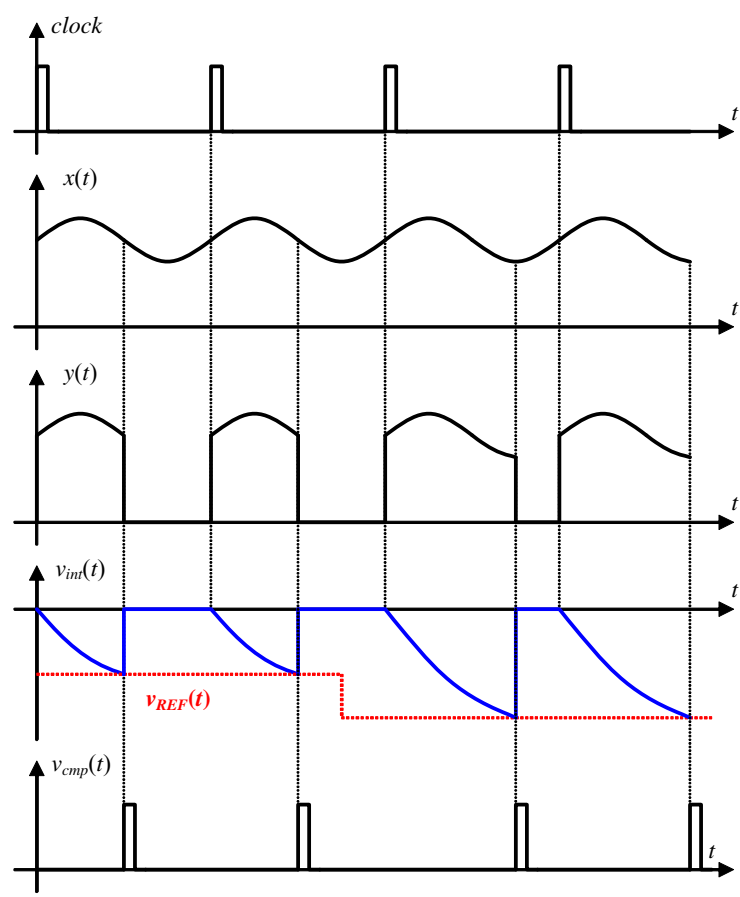

Fig. 5. Typical waveforms of one-cycle control.

The basic idea of the proposed control is to achieve an average inductor current during the time interval $T_{O N}$ equal to the output current. Thus, having into account that:

$$
i_{L}(t)+i_{\text {reg }}(t)=I_{\text {out }},
$$

the average value provided by the linear regulator block will tend to be zero. In addition, notice that the main difference with one-cycle control is that the linear regulator fixes the output voltage. In fact, the output voltage is given (and fixed) by the linear regulator. Therefore, according to before detailed, the new proposed technique can reject not only power disturbances, but load disturbances too.

The main idea of the proposed control is to achieve that the average value of the current flowing across the inductor during the time interval $T_{O N}\left(=\tilde{d}(t) T_{S}\right)$ equals to the average value of the current through the load during this interval. Therefore, considering that the output current is given by $I_{\text {out }}=I_{\text {reg }}+I_{L}$, the average current flowing through the linear regulator will tend to zero.

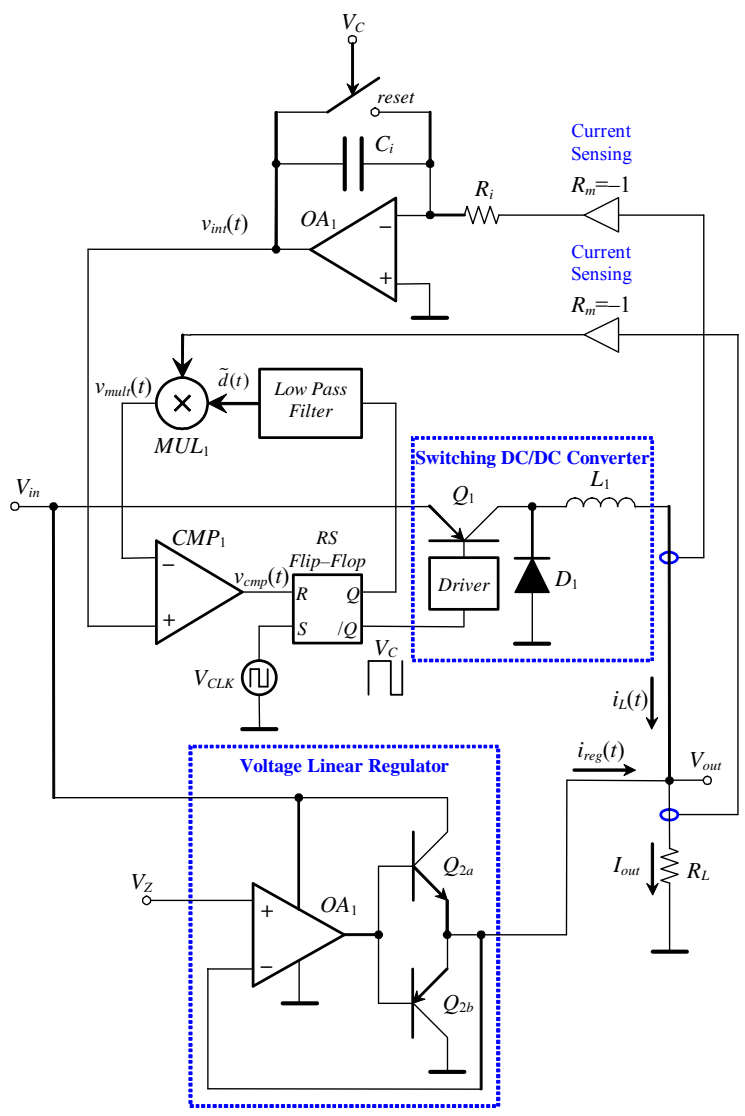

Fig. 6. Basic structure of a current-mode one-cycle linearassisted DC/DC converter.

On the one hand, the low-pass filter extract the average value of the duty cycle, $\tilde{d}(t)$, that multiplied by the output current $I_{\text {out }}$ (considered constant), provides a measure of the average value of the current flowing through the load during the interval $T_{O N}$. Thus, considering the gain factor of the current sensing element $R_{m}=1$, we have:

$$
v_{\text {mult }}(t)=\tilde{d}(t) I_{\text {out }}
$$

On the other hand, the analog integrator provides the measure of the average value of the current flowing across the inductor during the time interval $T_{O N}$, considering that the time constant is given by:

$$
R_{i} C_{i}=T_{S}
$$

Therefore:

$$
v_{\mathrm{int}}(t)=\frac{1}{R_{i} C_{i}} \int_{o}^{t} i_{L}(t) d t=\frac{1}{T_{S}} \int_{o}^{t} i_{L}(t) d t
$$

where the gain factor of the current sensing element $R_{m}=$ 1 (the negative sign compensates the additional inversion provided by the integrator). 
The average value of the switched variable at the switch output is guaranteed to be:

$$
\frac{1}{T_{S}} \int_{o}^{d T_{S}} i_{L}(t) d t=\tilde{d}(t) I_{\text {out }}
$$

in each cycle. Figure 7 shows the operating waveforms of the circuit when $v_{R E F}(t)$ is constant.

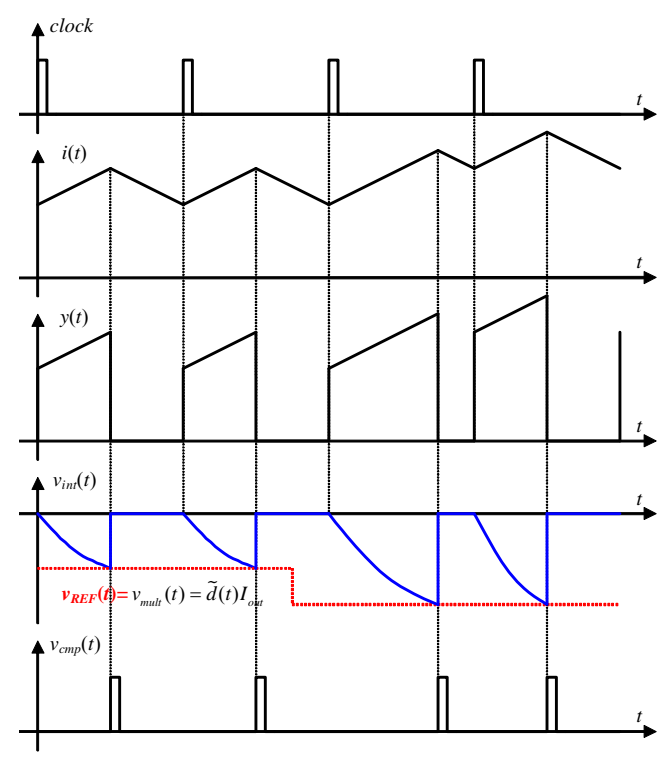

Fig. 7. Typical waveforms of the proposed linear-assisted converter with current-mode one-cycle control.

\section{Simulation Results}

In order to validate the presented structure of the currentmode one-cycle linear-assisted DC-DC converter in figure 6 , simulation results have been obtained from a system that provides $5.0 \mathrm{~V}$ at the output $V_{\text {out }}$. The value of the inductor is $L=100 \mu \mathrm{H}$. Figure 8 shows the circuit the start-up transient waveforms when the current-mode one-cycle linear-assisted DC/DC converter provides $2 \mathrm{~A}$ at the output $V_{\text {out }}$. Notice that the one-cycle control loop assures a value of the average current flowing through the linear stage near zero.

Figure 9 shows the transient response of the linear-assisted DC/DC converter to a step when the reference voltage increases from $5 \mathrm{~V}$ to $8 \mathrm{~V}$ at $500 \mu \mathrm{s}$.

\section{Conclusions}

In the presented paper, the design and simulation of a current-mode one-cycle control linear-assisted DC/DC converter has been carried out. The article has shown that linear-assisted DC/DC converters are suitable structures that allow to take advantages of the two classic alternatives in the design of power supply systems (voltage linear regulators and switching DC/DC converters). In addition, starting from this linear-assisted topology, and thanks to the general idea of one-cycle control, a current-mode one cycle linear-assisted DC/DC converter has been proposed. As a whole, the proposed DC/DC converter provides a good line regulation, thanks to the excellent power source disturbance rejection shown by the one-cycle control loop, a suitable load regulation thanks to the excellent load disturbance shown by the linear regulator and, finally, high efficiency shown by the switching converter.

\section{Acknowledgment}

This work has been partially funded by project TEC201015765/MIC from the Spanish Ministerio de Ciencia $e$ Innovación (MICINN) funds.

\section{References}

[1] X. Zhou, P. L. Wong, P. Xu, F. C. Lee, A. Q. Huang. "Investigation of Candidate VRM Topologies for Future Microprocessors". IEEE Transactions on Power Electronics, vol. 15 ( $\mathrm{n}^{\mathrm{o}}$ 6): pp. 1172-1182, November 2000.

[2] B. Arbetter, D. Maksimovic. "DC-DC Converter with Fast Transient Response and High Efficiency for LowVoltage Microprocessor Loads". IEEE Applied Power Electronics Conference, pp. 156-162. 1998.

[3] C. K. Chava, J. Silva-Martínez. "A Frequency Compensation Scheme for LDO Voltage Regulators". IEEE Transactions on Circuits and Systems-I: Regular Papers, vol. 51 (nº 6): pp: 1041-1050, June 2004.

[4] R. J. Milliken, J. Silva-Martínez, E. Sánchez-Sinencio. "Full On-Chip CMOS Low-Dropout Voltage Regulator". IEEE Transactions on Circuits and Systems-I: Regular Papers, vol. 54 (no 9): pp: 1879-1890, September 2007.

[5] V. Grupta, G. A. Rincón-Mora, P. Raha. "Analysis and Design of Monolithic, High PSR, Linear Regulator for SoC Applications". Proceedings of the IEEE International SoC Conference: pp. 311-315, 2004.

[6] R. W. Erickson, D. Maksimovic. "Fundamentals of Power Electronics". $2^{\text {nd }}$ edition, Ed. Kluwer Academic Publishers, 2001.

[7] J. G. Kassakian, M. F. Schlecht, G. C. Verghese. "Principles of Power Electronics". Ed. Addison-Wesley, 1991.

[8] N. Mohan, T. M. Underland, W. P. Robbins. "Power Electronics: Converters, Applications and Design". Ed. John Wiley \& Sons, 1989.

[9] P. Midya, F. H. Schlereth. 'Dual Switched Mode Power Converter'. IECON'89. Industrial Electronics Society: pp. 155-158, 1989.

[10] F. H. Schlereth, P. Midya. 'Modified Switched Power Convertor with Zero Ripple'. Proceedings of the $32^{\text {nd }}$ IEEE Midwest Symposium on Circuits and Systems (MWSCAS’90): pp. 517-520, 1990.

[11] A. Conesa, H. Martínez, J. M. Huerta. "Modeling of Linear \& Switching Hybrid DC-DC Converters". $12^{\text {th }}$ European Conference on Power Electronics and Applications (EPE 2007), September 2007.

[12] H. Martínez, A. Conesa,. "Modeling of Linear-Assisted DC-DC Converters". European Conference on Circuit Theory and Design 2007 (ECCTD 2007), 26 $6^{\text {th }}-30^{\text {th }}$ August 2007.

[13] K. M. Smedley, S. Cuk. "One-Cycle of Switching Converters". Proceedings of the $22^{\text {nd }}$ Power Electronics Specialists Conference.

(PESC'91): pp. 888-896. 1991.

[14] K. M. Smedley, S. Cuk. "One-Cycle of Switching Converters". IEEE Transactions on Power Electronics, vol. 10 ( $\left.{ }^{\circ} 6\right)$ : pp: 625-633, November 1995.

[15] Z. Hu, B. Zhang, W. Deng. "Feasibility Study on One Cycle Control for PWM Switched Converters". Proceedings of the $5^{\text {th }}$ 35th Annual IEEE Power 
Electronics Specialisrs Conference: pp. 3359-3365,

77, June 2004. 2004.

[16] Y. Wang, S. Shen. "Research on One-Cycle Control for Switching Converters". Proceedings of the $5^{\text {th }}$ World Congress on Intelligent Control and Automation: pp. 74-
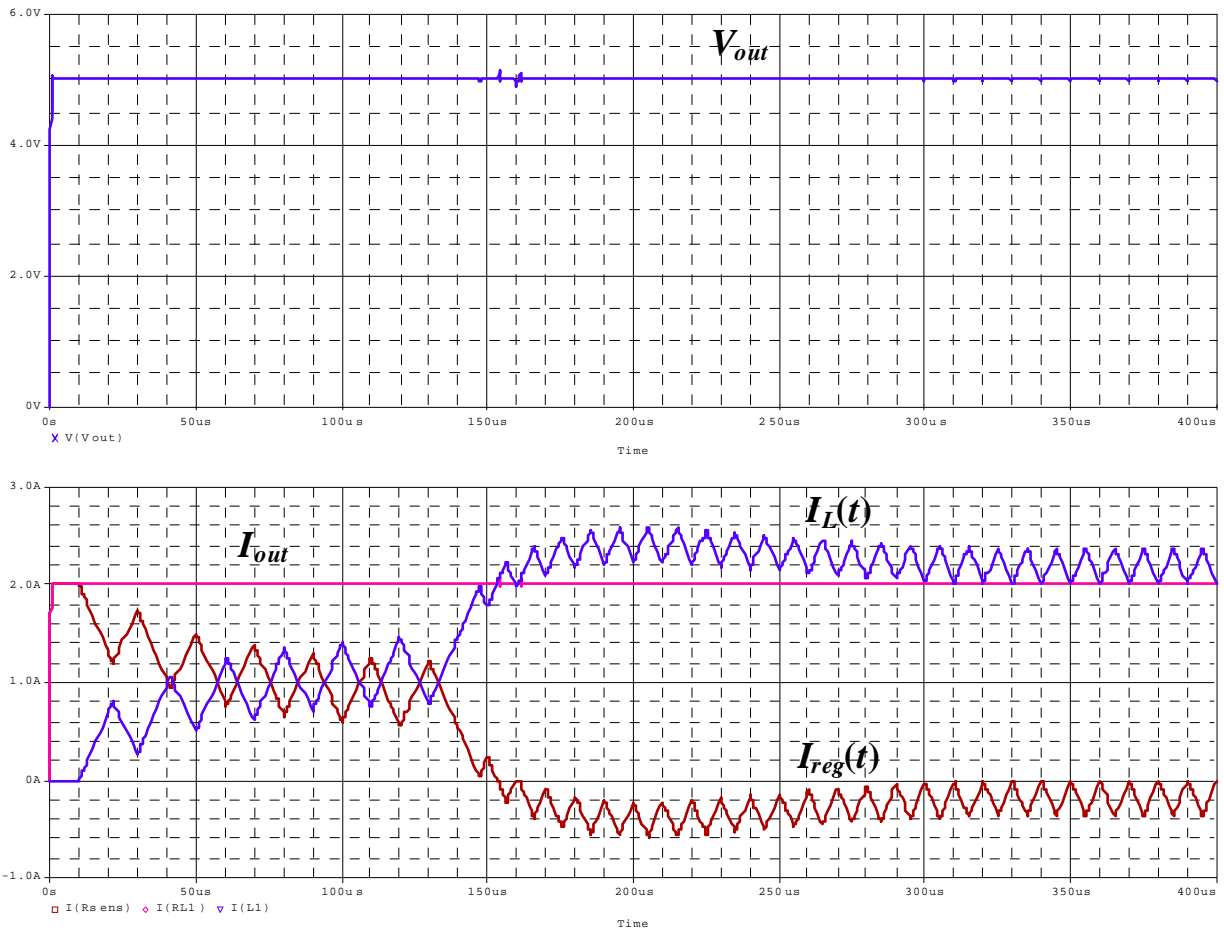

Fig. 8. Start-up transient waveforms when the current-mode one-cycle linear-assisted DC/DC converter provides $2 \mathrm{~A}$ at the output $V_{\text {out }}$. Notice that the one-cycle control loop assures a value of the average current flowing through the linear stage near zero.
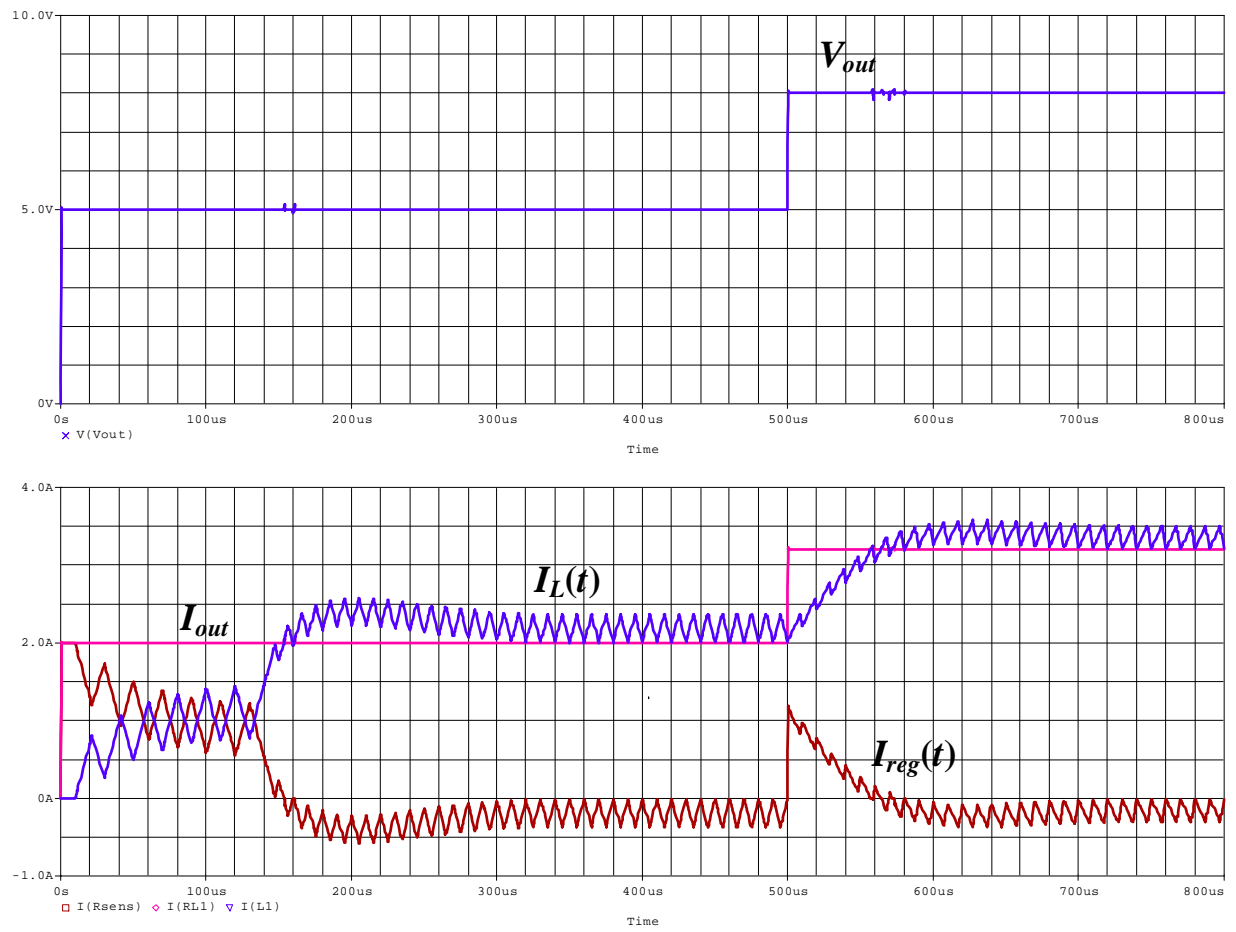

Fig. 9. Transient response of the linear-assisted DC/DC converter to a step when the reference voltage increases from $5 \mathrm{~V}$ to $8 \mathrm{~V}$ at 500 $\mu s$. 